\title{
РЕТРОСПЕКТИВА И ПЕРСПЕКТИВА РАЗВИТИЯ ТОРГОВО- ТАМОЖЕННЫХ ОТНОШЕНИЙ МЕЖДУ РОССИЕЙ И КИТАЕМ
}

\author{
T. ח. Лena \\ Байкальский государственный университет, г. Иркутск, Российская Федерация
}

Информация о статье

Дата поступления

6 декабря 2017 г.

Дата принятия к печати

21 мая 2018 г.

Дата онлайн-размещения 8 июня 2018 г.

\section{Ключевые слова}

Внешняя торговля; экономический потенциал; таможенные пошлины; взаимная выгода

\begin{abstract}
Аннотация
Актуальность внешнеэкономических связей для Российской Федерации с ближайшим соседом, обладающим мощнейшим на сегодняшний день экономическим, военным и ресурсным потенциалом, остается одной из наиболее очевидных, тем более что данные связи обусловлены не только географической близостью двух стран, но и всей историей становления и развития их экономических и политических взаимоотношений. В статье рассматриваются как перспективы, так и проблемы развития торгово-таможенных отношений между Китаем и Россией на современном этапе на основе анализа нормативных документов, регламентирующих внешнеэкономические связи стран-инопартнеров, и тезисов ученых с мировой известностью. Приводятся основные возможные направления развития внешнеторговых связей данных стран при реализации взаимных интересов, инвестиционной привлекательности с акцентом на внедрение информационных технологий при создании высокотехнологичных товаров и в рамках существующих международных соглашений. С учетом анализируемых прогрессивных тенденций в китайской экономике предлагаются наиболее приемлемые варианты путей развития экономики Российской Федерации. Основной задачей внешнеэкономического и геополитического сотрудничества КНР и РФ остается взаимовыгодное и постоянное увеличение объемов торговли и ужесточение таможенного контроля в отношении товарооборота данных стран в условиях глобализации экономики и быстро меняющейся политической и экономической ситуации на международной арене.
\end{abstract}

\section{RETROSPECTIVE AND PROSPECT OF CUSTOMS TRADE RELATIONS DEVELOPMENT BETWEEN RUSSIA AND CHINA}

\author{
Tatyana P. Lepa \\ Baikal State University, Irkutsk, the Russian Federation
}

\section{Article info}

Received

December 6, 2017

Accepted

May 21, 2018

Available online

June 8, 2018

\section{Keywords}

Foreign trade; economic potential; customs duties; mutual benefit

\begin{abstract}
For the Russian Federation, the relevance of foreign economic relations with the closest neighbouring country that has the most economic, military and resource strength remains one of the most obvious aspects, all the more so these communications are conditioned not only by the geographical proximity, but also by the whole history of establishment and development of economic and political relationships between these countries. The article considers the prospects and problems of customs trade relations development between China and Russia in the modern period, on the basis of the analysis of the statutory documents that regulate foreign economic relations of the partner countries, along with theses of the internationally acclaimed scientists. The author indicates the main potential directions for development of the foreign trade ties
\end{abstract}


of the countries aimed at realization of mutual interests under the current international agreements, investment attractiveness, emphasized on implementation of information technologies for the production of hi-tech goods. Regarding the analyzed progressive trends in development of the Chinese economy, the author proposes the most comfortable options of economic development for the Russian Federation. Mutually advantageous and constant increase in the volume of the trade and toughening of customs control towards commodity turnover in the age of economic globalization and rapidly changing political and economic situation on the global stage remains the key priority for the foreign economic and geopolitical cooperation between the People's Republic of China and the Russian Federation.

Экономические успехи Китая в конце $\mathrm{XX}$ - начале XXI в. являются наиболее притягательными для анализа мировым сообществом, и в частности экономистами Российской Федерации с целью изучения накопленного нашими соседями в этом направлении опыта. Начавшиеся в 1978 г. в Китае экономические реформы позволили стране увеличить валовый внутренний продукт (ВВП) почти в 6 раз к новому столетию. На начальном этапе проводимых Китаем реформ его ВВП был меньше российского на $23 \%$, а уже к концу XX в. он превышал российский в 6,2 раза. Объяснения такому «китайскому экономическому чуду» необходимо искать в том числе и в историческом прошлом этой страны. В экономике Древнего Китая, как и России, преобладало сельское хозяйство, при этом так же, как и во многих регионах России, оно носило характер рискованного. Но в Китае это было связано с засушливостью большинства земель, что требовало их гидратации и, как следствие, значительных физических и финансовых затрат. Огромную роль в развитии экономики Древнего Китая, как и России, сыграло купечество и активизация внутренней и внешней торговли. В XVII в. при освоении Сибири русскими казаками они впервые встречаются с жителями Китайской империи. В. С. Мясников утверждает, что в эту эпоху «торговля была эфффективным орудием китайского двора в контактах с иностранцами» [1, с. 13]. Официальное начало торговых отношений и определение границ между двумя государствами историки связывают с подписанием Нерчинского договора, заключенного 27 августа 1689 г. Хотя уже в период правления в Китае династий Мин (1368-1644 гг.) и Цин (1644-1912 гг.) развивалась торговля с российскими купцами, а позже открываются китайские банковские учреждения в Москве и Петербурге. В 1840-1860-х гг. в результате проводимой Китаем жесткой политики по защите внутреннего рынка от контрабанды наркотиков страна закрыла рынок для английских контрабандистов, что привело к военному конфликту с Великобританией. Проигрыш Китая в этих войнах открыл его морские порты для иностранцев и зафиксировал ввозные таможенные пошлины на самом низком уровне - в пределах $5 \%$, что не могло не повлиять на падение экономических показателей и на снижение привлекательности внешнеэкономических связей для Китая. В связи с этим ВВП Китая вплоть до 1950 г. застыл на одном уровне, в это же время в западных странах он вырос на порядок. 1949 год стал переломным в политике и экономике Китая: приход к власти коммунистов во главе с Мао Цзэдуном, объединение страны, акцент на индустриализацию и некоторый рост народного благосостояния. В это же время проводимая в Китае политика «большого скачка» повлекла последующий экономический кризис и массовый голод. 2 октября 1949 г. СССР установил с КНР дипломатические отношения, а экономики этих стран оставались замкнутыми на самих себя и носили плановый характер. В эту эпоху СССР помог Китаю создать базовые отрасли промышленности и их национализировать, провести коллективизацию сельского хозяйства, что позволило китайской экономике перейти к активному росту. Но новый советский курс Н. С. Хрущева по экономическому развитию СССР на основе «мирного сосуществования» с капиталистическими странами вызвал недовольство китайского руководства, и это привело к советско-китайскому дипломатическому расколу в конце 50-х гг. прошлого века. Проводимая в Китае с 1979 г. «политика реформ и открытости» была направлена на развитие кустарного и мелкотоварного производства, чему способствовала значительная численность населения, но это, в свою очередь, не способствовало разви- 
тию государственного сектора в экономике. Рыночная экономика с китайской спецификой сохранила свою многоукладность. Распад СССР в конце XX в. стал мировой трагедией, но в то же время он в лучшую сторону изменил отношения между КНР и возникшей на руинах СССР Российской Федерацией. Китай признает РФ преемницей СССР. Председатель КНР Цзян Цзэминь с 1993 г. продолжает реформы, начатые Дэн Сяопином, наращивая военный и экономический потенциал Китая; а в 2001 г. страна на выгодных для себя условиях вступает в ВТО, получает большие возможности в сорере занятости и инвестиций, повышает благосостояние народа, а также заявляет о возможном лидерстве среди стран Азиатско-Тихоокеанского региона. Соглашение между КНР и РФ от 5 марта 1992 г. предусмотрело взаимное предоставление режима наибольшего благоприятствования во внешней торговле и освобождение от уплаты таможенных пошлин и иных видов налогов. В постсоветский период вплоть до 2000 г. внешняя торговля между РФ и Китаем носила «челночный» характер, что позволяло наполнять российский рынок доступными, низкокачественными китайскими товарами. Для китайской экономики это был огромный плюс, так как КНР освоил огромный свободный рынок на границе с северным соседом. С началом восстановления российской экономики в 2000-х гг. наблюдается резкий рост товарооборота - до 4 раз, а в целом за период с 1995 по 2014 г. российский экспорт в Китай увеличился в 11,1 раза (с 3371 млн дол. до 37504 млн дол.), импорт - в 58,8 раза (с 865 млн дол. до 50884 млн дол. [2, с. 4445]) за счет активной продажи российских ресурсов, что было закреплено положениями соглашения о сотрудничестве между РФ и КНР в сырьевой отрасли, подписанного в 2009 г. Д. А. Медведевым и Ху Цзиньтао. Данным соглашением определялись перспективные направления сотрудничества до 2018 г., в соответствии с чем в приграничных регионах России и Китая должны были быть реализованы более 200 совместных проектов по разработке сырьевых месторождений в Восточной Сибири и на Дальнем Востоке и экспорту сырья в Китай для последующей переработки. В противовес словам заместителя генерального секретаря исследовательского центра «Один пояс, один путь» Сюй Вэньхуна «Россия имеет все шансы на то, чтобы стать для Китая партнером номер один в сырьевой отрасли» неко- торые российские политики (В. Поздняков, С. Луконин), ученые (А. Воскресенский, Ю. Галенович, В. Гельбрас, В. Холодков) и экономисты (В. Парамонов, А. Строков) высказывают опасения, что в дальнейшем Россия может превратиться в сырьевой придаток Китая. Тем более что 17 февраля 2009 г. было подписано соглашение, согласно которому в обмен на кредит в 25 млрд дол. РФ поставляет Китаю по нефтепроводу 300 млн т нефти, или 15 млн т в год, с 2011 по 2030 г. [3, с. 52].

В настоящее время в рамках рыночной экономики КНР и РФ стремятся к открытости во внешних отношениях, но «в Китае степень этой открытости регулируется государством, а в России ограничивается с 2014 г. системой западных санкций» [4]. Современная направленность взаимоотношений Китая и России была сорормулирована 16 июля 2001 г. в Договоре о добрососедстве, дружбе и сотрудничестве, который охватил значительное количество сорер двустороннего сотрудничества и срок действия которого составил 20 лет с возможностью продления на пять лет. Во исполнение этих договоренностей ежегодно организуются встречи глав правительств России и Китая. На постоянной основе несколько раз в год встречаются президент России Владимир Путин и председатель КНР Си Цзиньпин, при этом основное внимание на переговорах уделяется вопросам укрепления внешнеэкономического сотрудничества, прежде всего в энергетике, но оно не сводится только к экспорту углеводородного сырья из РФ взамен импорта товаров народного потребления. Заведующий кафедрой РЭУ имени Г. В. Плеханова Ю. Ровенский утверждает, что не стоит забывать o потенциале сотрудничества в области высоких технологий, в том числе в космической, военной отраслях и, конечно же, в финансовой сфере. Еще один немаловажный аспект заинтересованности Китая в российских ресурсах — наличие в России «запасов пресной воды, ведь уже сейчас Китай испытывает колоссальный дефицит этого ресурса» [5, с. 7], а также огромных ресурсов плодородных земель. Таким образом, принимая во внимание взаимные интересы стран, наиболее активным оказался рост внешнеэкономических отношений между РФ и КНР в период позитивной динамики их экономик в 2000-2014 гг., о чем свидетельствуют статистические данные (рис. 1). 


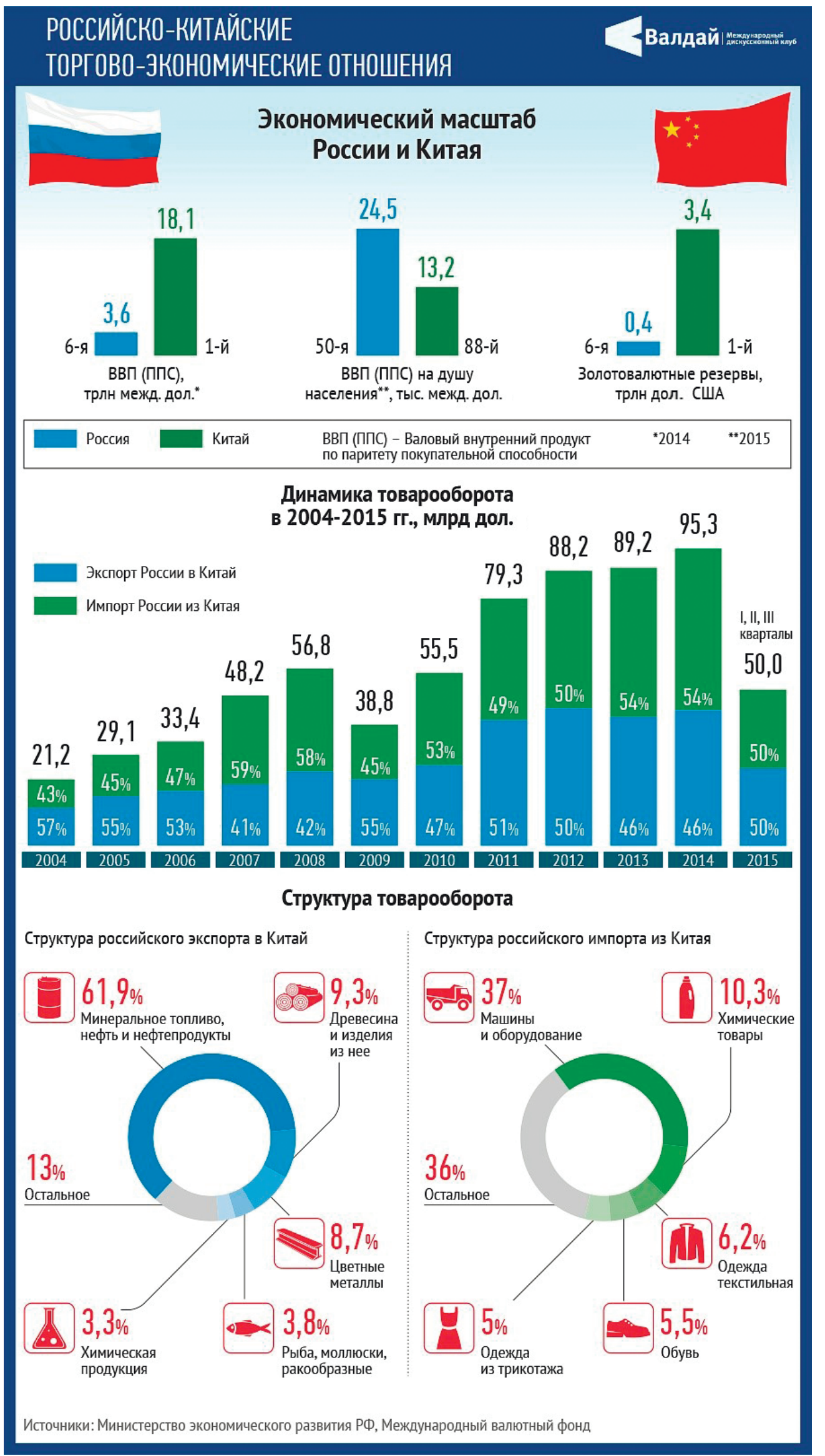


Несмотря на положительную динамику показателей в торговых связях РФ и КНР, в последние годы все очевиднее наблюдается рост определенных проблем, в частности, на это влияют международные процессы глобализации и интернационализации. Несмотря на введенные санкции, серьезно повлиявшие на показатели экспорта и импорта иностранных и российских товаров, во внешней торговле для России наиболее существенным остается торговый оборот со странами Евросоюза (свыше 43 \% в конце 2017 г.), в то время как со странами Азиатско-Тихоокеанского экономического сотрудничества - около 30 \%, странами СНГ - 12 \%, странами - членами Евразийского экономического союза - 8 \% (рис. 2).

В то же время с ближайшим соседом России внешнеторговый товарооборот в конце 2017 г., по данным ФТС России, составил всего $14 \%$, и в этих условиях взаимный интерес двух стран абсолютно не равнозначен: Россия заинтересована в Китае намного больше, чем Китай в России [6]. При этом наблюдается ежегодный рост товарооборота данных стран (табл.).

Для минимизации политической и экономической напряженности со странами Запада и США КНР и РФ выстраивают политику активного сотрудничества в рамках международных организаций преимущественно с азиатскими и латиноамериканскими странами - АТЭС, БРИКС, ШОС. Только Россия и
Китай (из состава БРИКС) являются одновременно государствами-членами и геополитического блока ШОС [7, с. 33]. Организация такого взаимодействия также актуальна в связи с вызовами международного финансового кризиса. На саммитах ШОС и встречах руководителей стран БРИКС разрешаются вопросы сохранения благоприятных тенденций развития многостороннего сотрудничества. Значительную роль в изменении глобального баланса сил в пользу АТР играет Китай [8, с. 191].

Учеными (Н. Рябченко, Ма Юцзюнь, Л. Забровская, Д. Владимирова, Л. Козлов, И. Ставров, А. Веремейчик, С. Белоглазова) делаются попытки решить экономические, политические и социальные проблемы во взаимоотношениях стран и во внутренней политике, для чего предлагается:

- укреплять инвестиционное партнерство (согласно статистике, прямые иностранные инвестиции в российскую экономику на порядок ниже инвестиций в китайскую экономику, также и китайские инвестиции в российскую экономику значительно превосходят российские инвестиции в китайскую);

- повысить уровень доверительного партнерства и стратегического взаимодействия между странами;

- сделать особый акцент на крупные проекты сотрудничества, развивать производства с высокой добавленной стоимостью и проекты инвестиций в сореру услуг, также

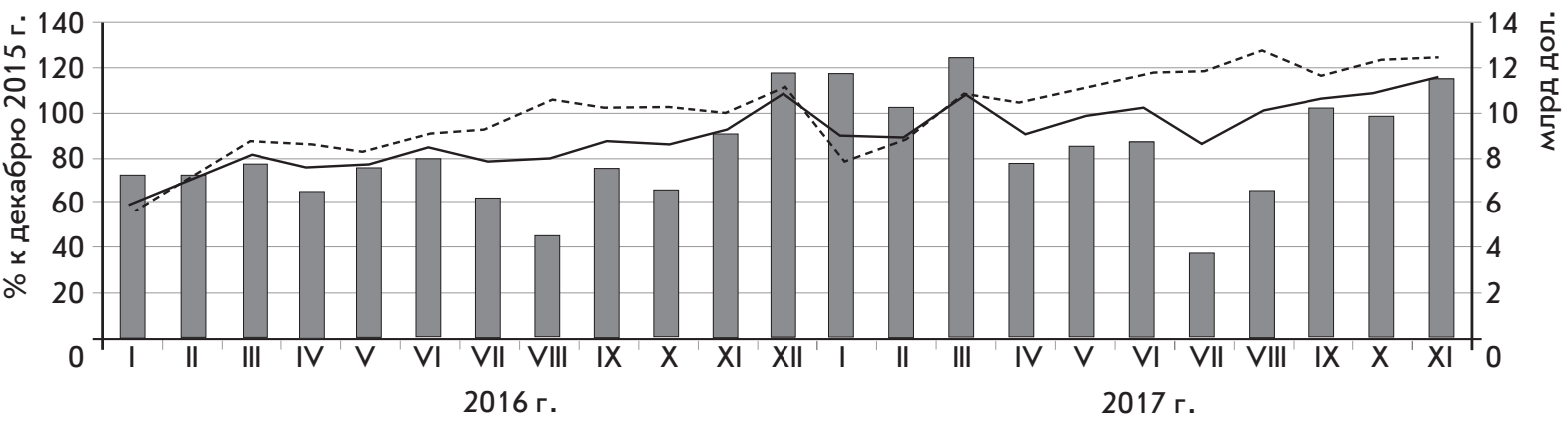

$\square$ Сальдо внешней торговли (правая ось)

- Экспорт

- - Импорт

Рис. 2. Сравнительные показатели внешнеторгового товарооборота России в период 2016-2017 гr.

Данные внешнеторгового оборота Российской Федерации и Китая за январь - ноябрь 2016 и 2017 гг., млн дол.

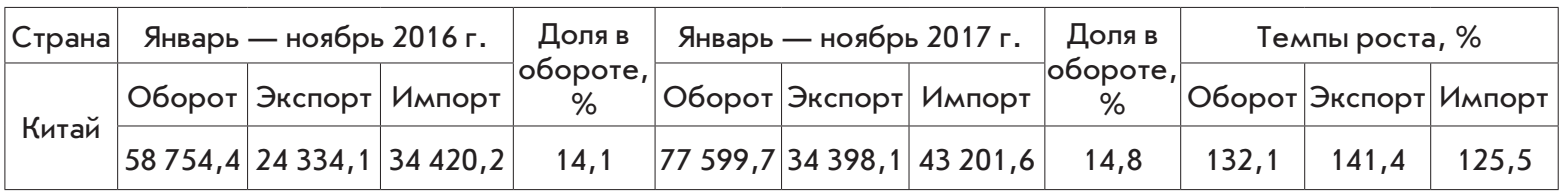

"Составлена по данным ФТС России. URL: http://www.customs.ru/index2.php?option=com_content\&view=artic le\&id $=25865$ \&ltemid $=1977$. 
обратить внимание на такие аспекты, как ресурсы, технологии и мощности, заимствовать положительный опыт друг друга [9, с. 207-208];

- активизировать межкультурные, научные и туристические контакты;

- регламентировать и контролировать социально-экономические факторы китайской миграции на Дальний Восток России и в Восточную Сибирь (это обусловлено тем, что для этих регионов характерны серьезный дефрицит трудовых ресурсов, нехватка средств, а также богатые запасы ресурсов [10]);

- рефрормировать традиционную систему образования на смежных с Дальним Востоком территориях Китая;

- стыковать стратегии развития приграничных регионов Китая и России, в первую очередь Дальнего Востока и Сибири (по утверждению В. Кулешова, «могущество Китая будет прирастать Сибирью, а богатство Сибири - Китаем» [11, с. 30]);

- поощрять российские и китайские компании, нацеленные на выход за рубеж и к прямым инвестициям;

- снижать дискриминационные тарифные ограничения во внешней торговле, в первую очередь со стороны российской таможни;

- снижать государственную нагрузку на экономику и проводить либеральную экономическую политику;

- увеличивать вложения в новые технологии и цифровизацию производства;

- создавать систему социального обеспечения, которая должна расти не за счет экспорта, а за счет внутреннего потребления;

- сократить имеющийся дисбаланс в торгово-экономических отношениях в области номенклатуры экспортируемых товаров (на сегодняшний день китайский экспорт - это продукты с высочайшей добавленной ценой, в то время как в экспорте из России преобладают необработанные ресурсы). «Доступ к ресурсам остается главной целью китайской внешней политики в любом регионе мира» $[12$, с. 73];

- снизить зависимость экономики РФ от нестабильности экономики КНР.

Значительную роль в активизации взаимной торговли играют как решения правительств стран, так и таможенные службы данных стран. Так, согласно данным Главного таможенного управления Китая, торговый оборот между Китаем и Россией в 2017 г. в долларовом эквиваленте увеличился на 20,8 \% и составил порядка 84 млрд дол. ИМпорт китайских товаров в РФ вырос на 14,8\% и составил 42,9 млрд дол. , в то время как экс- порт российских товаров в Китай увеличился на 27,7 \% и достиг уровня 41,2 млрд дол. В 2017 г. Россия обогнала Саудовскую Аравию по поставкам нефти в Китай. А по данным Федеральной таможенной службы России, внешнеторговый оборот с Китаем в конце 2017 г. по сравнению с аналогичным периодом 2016 г. вырос на 32,1\% за счет роста показателей как по экспорту - на 41,4\%, так и по импорту - на 25,5\%.

Несмотря на незначительный объем товарооборота между РФ и КНР, Китай остается главным партнером России в международных проектах. В частности, Китай - это основной лидер в проекте «Экономический пояс Шелкового пути». Руководители России и Китая поставили цель нарастить в ближайшие годы объемы взаимного товарооборота до 100 млрд дол., а в перспективе - до 200 млрд дол. Такие амбициозные планы невозможно реализовать без кардинальных изменений в таможенном регулировании товаропотоков с целью ускорения и облегчения процедур таможенного контроля и выпуска товаров. В связи с этим в 2017 г. таможенные органы КНР и РФ расширили возможности по взаимному признанию результатов таможенного контроля как на Дальнем Востоке, так и в Сибирском регионе. Это должно ускорить пересечение границы транспортными средствами на 10-20 минут, а также увеличить объем и стоимость перемещаемых товаров. Кроме того, таможенные органы стран начали реализовывать проект по обмену информацией, полученной в результате контроля с помощью инспекционно-досмотровых комплексов, с целью получения более полной информации о товарах и пресечения криминального провоза грузов через границу, а также роста доверия между странами. Таможенными службами Китая и России создано семь китайско-российских рабочих групп по основным направлениям их деятельности. «В таможенной сорере реализуется порядка десяти совместных проектов» [13]. Один из основных - проект «Зеленый коридор», который позволил уменьшить время прохождения таможенного контроля китайских товаров практически в 2 раза - до 40 минут. В 2017 г. во исполнение положений Киотской конвенции таможенные органы РФ и КНР подписали соглашение о сотрудничестве в сфере реализации системы управления рисками, что в будущем создаст для законопослушных лиц наиболее комфортные условия ведения внешней торговли, а 
в случае обнаружения криминальных схем позволит пресечь контрабандные пути и выявить правонарушителей.

С целью реализации либеральной политики во внешней торговле Китай на постоянной основе поднимает вопросы о дополнительных сокращениях таможенных тарифов, и на сегодняшний день более 7 тыс. товаров из Китая не облагается таможенными пошлинами.

В своей экономической политике России необходимо учитывать основные направления и цели, которые устанавливает для себя $\mathrm{KHP}$, реализуя свои политические и экономические замыслы на международной арене, такие как:

- наладить отношения (в том числе и территориального характера) и осуществлять взаимовыгодное сотрудничество с ведущими странами мира, среди которых Российская Федерация. Решению пограничных проблем между РФ и КНР, длившихся с 1964 г., способствовало подписание странами в 2005 г. Соглашения о российско-китайской государственной границе в восточных регионах этих стран;

- обеспечить статус КНР как сверхдержавы за счет усиления дипломатического, политического, экономического и военного влияния и ослабить влияние США, в первую очередь в регионе Юго-Восточной Азии;
- усилить влияние в различных международных и региональных организациях, таких как ШОС, АТЭС и БРИКС, а также влияние на страны Азиатско-Тихоокеанского и Центрально-Азиатского регионов. "Для России ЦАР также является одним из важнейших внешнеполитических приоритетов, это придает особую важность вопросу политики Китая в данном регионе» [14, с. 19].

Можно утверждать, что стратегическое взаимодействие КНР и РФ играет значительную роль в обеспечении стабильности и безопасности в мировом сообществе в целом и усиливает позиции России на международной арене. А в области военных разработок Россия остается для Китая ключевым партнером. Совместная деятельность стран позволяет снизить уровень угроз в области наркоторговли, экстремизма, терроризма, бандитизма, сепаратизма. КНР остается для РФ серьезной альтернативой и противовесом в торговле сырьем с западными странами. Рост производства в Китае, его заинтересованность в российских ресурсах еще больше скрепляют этот союз, необходимо только, чтобы Россия не допустила исключительной переориентации на китайский рынок. Но роль китайского рынка для России ценна также и тем, что внешняя торговля с КНР снижает воздействие американских и западных санкций на российскую экономику.

\section{СПИСОК ИСПОЛЬЗОВАННОЙ ЛИТЕРАТУРЫ}

1. Мясников В. С. Россия и Китай: историческое прошлое, современность и перспективы отношений (Семь особенностей и семь моделей отношений России с Китаем) / В. С. Мясников / / Российско-китайские исследования. - 2017. - № 1. - С. 10-21.

2. Суходолов Я. А. Современное состояние и перспективы развития внешней торговли России с Китаем / Я. А. Суходолов // Российско-китайские исследования. - 2017. - № 1. - С. 43-49.

3. Акимова О. Е. Перспективы торгово-экономического сотрудничества России и Китая / О. Е. Акимова, В. В. Исаев / / Известия Волгоградского государственного технического университета. — 2013. - Т. 16, № 11 (114). - С. 51-55.

4. Тагаров Ж. 3. Развитие экономических отношений России и Китая: уроки истории [Электронный ресурс] / Ж. З. Тагаров / / Baikal Research Journal. - 2015. - Т. 6, № 5. - Режим доступа: http: / /brj-bguep.ru/ reader/article. aspx?id=20384. - DOI: 10.17150/2411-6262.2015.6(5).12.

5. Белолипецкая А. В. Экономические взаимоотношения России и Китая [Электронный ресурс] / А. В. Белолипецкая, С. А. Комаров // Концепт. - 2015. - № S9. - C. 6-10. - Режим доступа: http: //e-koncept. $\mathrm{ru} / 2015 / 75145 . \mathrm{htm}$

6. Цвигун И. В. Повышение национальной конкурентоспособности России в контексте развития торговоэкономического сотрудничества с Китаем [Электронный ресурс] / И. В. Цвигун, М. А. Балашова, Я. А. Суходолов / / Baikal Research Journal. - 2015. - Т. 6, № 5. - Режим доступа: http: / /brj-bguep.ru/reader/article. aspx?id=20380. - DOl: 10.17150/2411-6262.2015.6(5).10.

7. Марцева Т. Г. Взаимодействие Китая и России в рамках БРИКС / Т. Г. Марцева, Я. Г. Небылова // KANT. - 2015. - № 1 (14). - C. 30-37.

8. Сирота Н. М. Геостратегия Китая и позиционирование России / Н. М. Сирота / / Исторические, философские, политические и юридические науки, культурология и искусствоведение. Вопросы теории и практики. - 2014. - № 1-1 (39). - С. 191-195.

9. Белоглазов Г. П. Россия и Китай в современном мире / Г. П. Белоглазов // Россия и АТР. - 2014. № 2 (84). - C. 207-212.

10. Ван Нана. Укрепление экономического сотрудничества регионов России и Китая при условии взаимодополняемости ресурсов несмежных районов [Электронный ресурс] / Ван Нана // Baikal Research Journal. - 2016. - T. 7, № 5. - Режим доступа: http: //brj-bquep.ru/reader/article.aspx?id=20921. - DOI: $10.17150 / 2411-6262.2016 .7(5) .12$ 
11. Кулешов В. В. Развитие Сибири и грани сотрудничества с Китаем / В. В. Кулешов // Экономическая наука современной России. - 2002. - № S1. - С. 28-33.

12. Каплан Р. География китайской мощи. Как далеко может распространиться влияние Китая на суше и на море? / Р. Каплан / / Россия в глобальной политике. - 2010. — № 4. - С. 68-82.

13. Лепа Т. П. Проблемы организации международного таможенного сотрудничества на современном этапе [Электронный ресурс] / Т. П. Лепа / / Baikal Research Journal. — 2016. - T. 7, № 4. - Режим доступа: http: / / brj-bguep.ru/reader/article. aspx?id=20852. — DOI: 10.17150/2411-6262.2016.7(4).17.

14. Давыдов 3. В. Экономическая политика Китая в Центрально-Азиатском регионе и ее последствия для России / З. В. Давыдов / / Известия Восточного института. - 2015. — № 2 (26). - С. 19-29.

\section{REFERENCES}

1. Myasnikov B. C. Russia and China: the Historical Past, the Present and Prospects of Relations (Seven Features and Seven Models of Russia's Relations with China). Rossiisko-kitaiskie issledovaniya = Russian and Chinese Studies, 2017, no. 1, pp. 10-21. (In Russian).

2. Sukhodolov Ya. A. Current State and Prospects of the Russian-Chinese Foreign Trade Development. Rossiiskokitaiskie issledovaniya = Russian and Chinese Studies, 2017, no. 1, pp. 43-49. (In Russian).

3. Akimova O. E., Isaev V. V. Prospects of Trade and Economic Cooperation between Russia and China. Izvestiya Volgogradskogo gosudarstvennogo tekhnicheskogo universiteta = Izvestiya of Volgograd State Technical University, 2013, vol. 16, no. 11 (114), pp. 51-55. (In Russian).

4. Tagarov Zh. Z. Development of Economic Relations of Russia and China: Lessons of History. Baikal Research Journal, 2015, vol. 6, no. 5. Available at: http: //brj-bguep.ru/reader/article.aspx?id=20384. DOl: 10.17150/24116262.2015.6(5).12. (In Russian).

5. Belolipetskaya A. V., Komarov S. A. Economic Relationship between Russia and China. Kontsept=Koncept, 2015, no. S9, pp. 6-10. Available at: http: / /e-koncept.ru/2015/75145.htm. (In Russian).

6. Tsvigun I. V., Balashova M. A., Sukhodolov Ya. A. Increasing Russia's National Competitiveness in the Context of Developing Trade and Economic Cooperation with China. Baikal Research Journal, 2015, vol. 6, no. 5. Available at: http: / / brj-bguep.ru/reader/article.aspx?id=20380. DOI: 10.17150/2411-6262.2015.6(5).10. (In Russian).

7. Martseva T. G., Nebylova Ya. G. Interaction between China and Russia as Part of the BRICS. KANT, 2015, no. 1 (14), pp. 30-37. (In Russian).

8. Sirota N. M. Geostrategy of China and Positioning of Russia. Istoricheskie, filosofskie, politicheskie i yuridicheskie nauki, kul'turologiya i iskusstvovedenie. Voprosy teorii i praktiki=Historical, Philosophical, Political and Law Sciences, Culturology and Study of Art. Issues of Theory and Practice, 2014, no. 1-1 (39), pp. 191-195. (In Russian).

9. Beloglazov G. Russia and China in the Modern World. Rossiya i ATR=Russia and the Pacific, 2014, no. 2 (84), pp. 207-212. (In Russian).

10. Wang Nana. Strengthening Economic Cooperation of Russian and Chinese Regions in Terms of Complementarity of Noncontiguous District Resources. Baikal Research Journal, 2016, vol. 7, no. 5. Available at: http: //brj-bguep. ru/reader/article. aspx?id=20921. DOI: 10.17150/2411-6262.2016.7(5).12. (In Russian).

11. Kuleshov V. V. Development of Siberia and the Dimensions of Partnership with China. Ekonomicheskaya nauka sovremennoi Rossii = Economic Science of Modern Russia, 2002, no. S1, pp. 28-33. (In Russian).

12. Kaplan R. Geography of the Chinese Might. How Far the Influence of China May Spread on Land and Sea? Rossiya v global'noi politike = Russia in global Affairs, 2010, no. 4, pp. 68-82. (In Russian).

13. Lepa T. P. Problems of Organization for International Customs Cooperation at the Present Stage. Baikal Research Journal, 2016, vol. 7, no. 4. Available at: http://brj-bguep.ru/reader/article.aspx?id=20852. DOI: 10.17150/2411-6262.2016.7(4).17. (In Russian).

14. Davydov Z. V. Economic policy of China in the Central Asia Region and its Impact on Russia. Izvestiya Vostochnogo instituta = Eastern Institute Bulletin, 2015, no. 2 (26), pp. 19-29. (In Russian).

\section{Информация об авторе}

Лепа Татьяна Павловна - старший преподаватель, кафедра конституционного и административного права, Байкальский государственный университет, 664003, г. Иркутск, ул. Ленина, 11, e-mail: 777taliana777@rambler.ru.

\section{Для цитирования}

Лепа Т. П. Ретроспектива и перспектива развития торгово-таможенных отношений между Россией и Китаем / Т. П. Лепа / / Известия Байкальского государственного университета. - 2018. - Т. 28, № 2. - C. 284-291. - DOI: $10.17150 / 2500-$ 2759.2018.28(2).284-291.

\begin{abstract}
Author
Tatyana P. Lepa - Senior teacher, Constitutional and Administrative Law Department, Baikal State University, 11 Lenin St., 664003, Irkutsk, the Russian Federation, e-mail: 777taliana777@rambler.ru.
\end{abstract}

\section{For citation}

Lepa T. P. Retrospective and Prospect of Customs Trade Relations Development between Russia and China. Izvestiya Baykal'skogo gosudarstvennogo universiteta = Bulletin of Baikal State University, 2018, vol. 28, no. 2, pp. 284-291. DOI: 10.17150/25002759.2018.28(2).284-291. (In Russian). 